\title{
Lachancea mirantina sp. nov., an ascomycetous yeast isolated from the cachaça fermentation process
}

Correspondence

Marcos Antonio de Morais, Jr marcos.morais@pesquisador. cnpq.br

\author{
Luciana Filgueira Pereira, ${ }^{1}$ César Raimundo Lima Costa, $\mathrm{Jr},{ }^{2}$ \\ Bereneuza Tavares Ramos Valente Brasileiro ${ }^{3}$ \\ and Marcos Antonio de Morais, $\mathrm{Jr}^{1,2}$
}
${ }^{1}$ Grupo Interdepartamental de Engenharia Metabólica, CCB, Universidade Federal de Pernambuco, Recife, PE 50760-901, Brazil
2Departamento de Genética, CCB, Universidade Federal de Pernambuco, Recife, PE 50760-901, Brazil
${ }^{3}$ Centro de Biologia e Saúde, Universidade Católica de Pernambuco, Recife, PE 50050-900, Brazil

Industrial alcohol fermentation using sugar cane juice or molasses is a complex environment in which many yeast species are found, some as contaminants and others just as adventitious organisms (da Silva-Filho et al., 2005; Basílio et al., 2008). The influence of each species on the alcohol fermentation process is still unknown. Cachaça is a typical Brazilian beverage that is produced from sugar cane juice fermentation. The fermented must from this process is then distilled to produce a spirit with about $40^{\circ}$ GL that can be consumed directly or after ageing in oak barrels (Oliveira et al., 2005). A complex succession of yeast species has been observed during the course of this type of fermentation (Pataro et al., 2000; Gomes et al., 2007; Vila Nova et al., 2009). Previously, we reported the differences in yeast populations associated with the technological levels in the cachaça distilleries, with the highest number of species being observed for the less controlled processes (Vila Nova et al., 2009). One of those yeasts, isolate $\operatorname{SPC} 2(7)^{\mathrm{T}}$, was genetically related to Zygosaccharomyces sp. IFO 11066 isolated from sake fermentation in Japan (Vila Nova et al., 2009). In the present work, we have extended the identification of that isolate using conventional biochemical and molecular taxonomic approaches by sequencing of the D1/D2 region of the large subunit of the rRNA gene (Kurtzman \& Robnett, 1998).

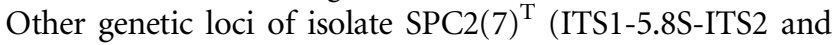

The GenBank/EMBL/DDBJ accession number for the 26S D1/D2 rDNA sequence of Lachancea mirantina URM $5925^{\top}$ is FJ666084.
EFA1 gene) were also sequenced for confirmatory multigene analysis (Kurtzman \& Robnett, 2003). Using the phylogenetic species concept, a novel species, Lachancea mirantina sp. nov., isolated from the cachaça fermentation process, is proposed.

\section{Yeast isolation and characterization}

The yeast isolate $\operatorname{SPC} 2(7)^{\mathrm{T}}\left(=\mathrm{URM} 5925^{\mathrm{T}}=\mathrm{CLIB} 1160^{\mathrm{T}}\right.$ $=\mathrm{CBS} 11717^{\mathrm{T}}$ ) was isolated from the fermentation process for cachaça production in the distillery Mirante da Cachaça, located in the city of Paudalho $\left(07^{\circ} 53^{\prime} 48^{\prime \prime} \mathrm{S} 35^{\circ} 10^{\prime} 47^{\prime \prime} \mathrm{W}\right.$, $69 \mathrm{~m}$ above sea-level), Pernambuco State, Brazil. The isolation procedure and fermentation conditions have been reported by Vila Nova et al. (2009) and the strain was characterized by using standard methods (Yarrow, 1998).

\section{DNA sequencing and cladistic analysis}

The variable domain D1/D2 of the 26S rRNA gene of strain URM $5925^{\mathrm{T}}$ was amplified using primers NL-1 (5'GCATATCAATAAGCGGAGGAAAAG-3') and NL-4 (5'GTCCGTGTTTCAAGACGG-3'), according to de Souza Liberal et al. (2007). The EFA1 gene was amplified using primers yEF1-for (5'-GTAAGGGTTCTTTCAAGTACGC$\left.3^{\prime}\right)$ and yEF1-rev (5'-GGAGTCACCAAAGACGTTACC$\left.3^{\prime}\right)$ designed from the conserved $5^{\prime}$-terminal and $3^{\prime}$ terminal regions of the Zygosaccharomyces gene deposited at the NCBI database (GenBank accession nos AF402076.1, 
AF402075.1, AF402059.1, AF402058.1 and AF402055.1). Sequences were analysed by CLUSTAL X multiple alignment in the BioEdit sequence alignment editor 7.0.5.3v (Hall, 1999). The completely conserved sequences were used for primer design with the same editor. The amplification products of ITS, D1/D2 and EFA1 loci were purified by using the Wizard PCR Preps DNA purification system (Promega), checked for purity by agarose gel electrophoresis and for concentration by comparing with $\lambda$-HindIII marker (Invitrogen), and submitted to DNA sequencing after being labelled using the BigDye Terminator v3.1 cycle sequencing kit (Applied Biosystems). Labelled products were analysed in an ABI Prism 3100 DNA sequencer (Applied Biosystems). Nucleotide sequences were analysed in BioEdit and submitted to BLASTN at the NCBI. The most similar sequences were downloaded in FASTA format and aligned with CLUSTAL $\mathrm{W}$ of the BioEdit program. Aligned regions were analysed for the phylogenetic signal using Tree-puzzle v. 5.2 software. A cladistic tree was reconstructed using PAUP 4.0 (Swofford, 2002) by the neighbourjoining method (Saitou \& Nei, 1987) with the Kimura-2 parameter nucleotide substitution model (Kimura, 1980) and by the maximum-likelihood method (Felsenstein, 1985). Results were checked for the best evolution model by the program MODELTEST 3.7 (Posada \& Crandall, 1998). Reliability was tested by bootstrap analysis with 1000 pseudo-replicates.

\section{Molecular identification of strain URM $5925^{\top}$}

Previous cladistic analysis with 26S D1/D2 nucleotide sequences was performed with yeasts isolated from different cachaça fermentation processes. In those analyses, strain URM $5925^{\mathrm{T}}$ was identified and the D1/D2 region of this isolate showed $100 \%$ sequence similarity with that of a yeast designated Zygosaccharomyces sp. strain IFO 11066 (Vila Nova et al., 2009), which had been isolated in Japan from sake fermentation (data not published). Both URM $5925^{\mathrm{T}}$ and Zygosaccharomyces sp. IFO 11066 clustered within the Zygosaccharomyces clade together with Zygosaccharomyces fermentati and Zygosaccharomyces cidri and were originally considered to be species of the genus Zygosaccharomyces (Vila Nova et al., 2009). However, those two species were recently reclassified within a new genus, Lachancea, that was separated from the genus Zygosaccharomyces by phylogenetic analysis (Kurtzman, 2003). Although they were closely related, strains URM $5925^{\mathrm{T}}$ and IFO 11066 defined a distinct branch in the cluster of what is now designated Lachancea cidri and Lachancea fermentati; this analysis was heavily supported by all clustering methods tested (Vila Nova et al., 2009). Therefore, it is suggested that these isolates represent a novel species of the genus Lachancea.

In view of this possibility, the molecular analysis of strain URM $5925^{\mathrm{T}}$ was extended to include other molecular markers. D1/D2 nucleotide sequence analysis was repeated for strain URM $5925^{\mathrm{T}}$ (GenBank accession no. FJ666084) and $100 \%$ similarity to the sequence of strain IFO 11066 was confirmed; compared with the L. fermentati sequence, 17 nt substitutions were observed, which represents $3.5 \%$ (17/493) nucleotide divergence. The limit of $1 \%$ nucleotide divergence is now widely accepted as a guideline for the delimitation of species for the ascomycetous yeasts (Kurtzman \& Robnett, 1998), although some exceptions have been reported (Lachance et al., 2003). In view of this assumption, strains URM $5925^{\mathrm{T}}$ and IFO 11066 belong to a novel species in the genus Lachancea. A similar analysis was performed by sequencing the ITS and EF- $1 \alpha$ loci. The ITS locus of strain URM $5925^{\mathrm{T}}$ (accession no. FJ666085.1) showed $94 \%$ similarity (4\% gaps) to that of L. fermentati (AY046206), $93 \%$ similarity (2\% gaps) to that of $L$. cidri (AY046205) and $93 \%$ similarity (2\% gaps) to that of Lachancea thermotolerans (FJ153217). In the case of the EF$1 \alpha$ locus of strain URM $5925^{\mathrm{T}}$ (GenBank accession no. GQ292877), BLAST results showed $94 \%$ similarity (no gaps) to L. fermentati (AF402076). The cladistic analysis tree of 26S D1/D2 nucleotide sequences included the eight other recently described species of the genus. Recently, three novel species in this genus have been proposed: Lachancea meyersii was isolated from mangrove habitats in the northern Bahamas Islands and can be distinguished from other members of the genus Lachancea by the combined characteristics of lack of growth on galactose and growth on maltose (Fell et al., 2004); Lachancea dasiensis was isolated from leaves and soil in Thailand and was closely related physiologically and phylogenetically to $L$. thermotolerans and Lachancea waltii (Lee et al., 2009); and Lachancea nothofagi was isolated from trees in native forests in Patagonia, Argentina, and belongs to the $L$. thermotolerans clade (Mestre et al., 2010). Branch separation was highly supported by the cladistic analysis and showed that $L$. mirantina sp. nov. now represents the ninth species of this genus (Fig. 1). According to the phylogenetic species concept and the place of isolation, a novel species of the genus Lachancea, Lachancea mirantina sp. nov., is proposed.

\section{Latin diagnosis of Lachancea mirantina Pereira, Costa, Brasileiro, Rosa et Morais sp. nov.}

In medio liquido post dies 3 cellulae singulae aut binae; cellulae ovoidae aut ellipsoideae $(2-4 \times 3-5 \mu \mathrm{m})$. Cultura in agaro malti post dies $5\left(28{ }^{\circ} \mathrm{C}\right)$ parva, convexa, glabra et candida. In agaro farinae Zea mays post dies 14, mycelium nec pseudomycelium non formantur. Species homothallica. Asci continentes 1-4 ascosporas globosae. Glucosum, sucrosum et maltosum fermentatur. Glucosum, galactosum (lente), sucrosum, maltosum (lente), trehalosum (lente), raffinosum (lente), inulinum (lente), glycerolum, acidum lacticum (lente), glucitolum, mannitolum, salicinum et xylitolum (lente) assimilantur, at non L-sorbosum, cellobiosum, lactosum, melibiosum, melezitosum, amylum solubile, Dxylosum, L-arabinosum, D-arabinosum, D-ribosum, L-rhamnosum, ethanolum, erythritolum, ribitolum, galactitolum, acidum succinicum, acidum citricum, myo-inositolum, 


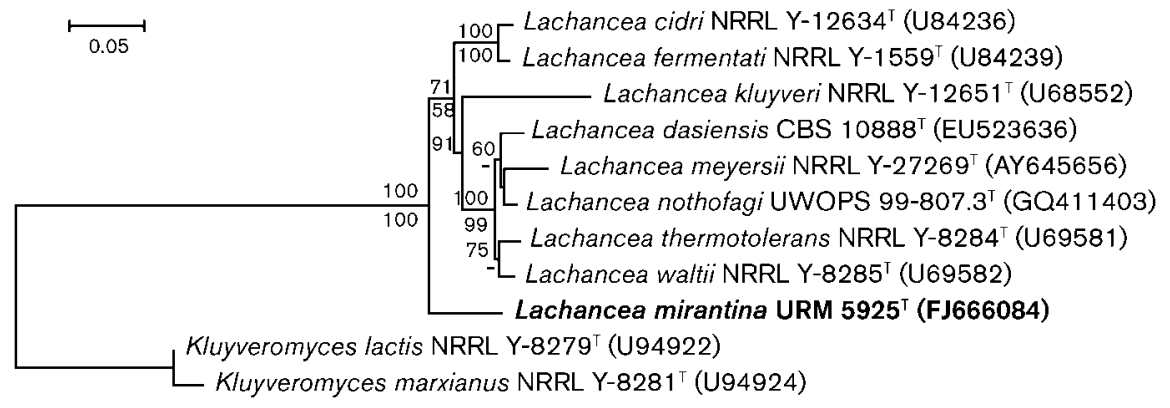

Fig. 1. Maximum-likelihood tree recovered in a neighbour-joining framework with a GTR +I and Distance corrected with Kimura two-parameter model of sequence evolution, with all characters within the D1/D2 26S dataset in the clade Lachancea. Values above the branches represent support values from Distance analysis with 1000 bootstrap replicates. Values below the branches represent maximum-likelihood (1000 replicates) bootstrap percentages. Two species of the genus Kluyveromyces were used as the outgroup. Bar, 0.05 substitutions per site.

methanolum, hexadecanum, acetona, ethyl acetas, 2-propanolum nec acidum gluconicum. N-Acetylglucosaminum, ethylaminum et cadaverinum assimilantur, at non lysinum, natrium nitricum nec natrium nitrosum. Ad crescentiam vitamina externa necessaria sunt. Augmentum in $30{ }^{\circ} \mathrm{C}$, at non $37^{\circ} \mathrm{C}$. Habitat fermentatus cachaça in Brazil. Typus URM $5925^{\mathrm{T}}$. In collectione zymotica, Centre International de Ressources Microbiennes, Grignon ( $s u b$ no. CLIB $1160^{\mathrm{T}}$ ) et Centraalbureau voor Schimmelcultures, Trajectum ad Rhenum (sub no. CBS $11717^{\mathrm{T}}$ ) typus stirps deposita est.

\section{Description of Lachancea mirantina Pereira, Costa, Brasileiro, Rosa \& Morais sp. nov.}

Lachancea mirantina (mi.ran.ti'na. N.L. fem. adj. mirantina pertaining to the place of isolation, the distillery Mirante da Cachaça).

In yeast extract $(0.5 \%)$-glucose $(2 \%)$ broth after 3 days at $28{ }^{\circ} \mathrm{C}\left( \pm 2{ }^{\circ} \mathrm{C}\right)$, cells are ovoid to ellipsoidal $(2-4 \times 3-$ $5 \mu \mathrm{m})$, with simple budding. On yeast extract-malt extract (YM) agar after 5 days at $28{ }^{\circ} \mathrm{C}\left( \pm 2{ }^{\circ} \mathrm{C}\right)$, yeast colonies are white, convex, smooth and opalescent. After 14 days on cornmeal agar in Dalmau plates, neither pseudomycelium nor true mycelium are produced. After 2 days on agar media with low nitrogen/carbon ratio (e.g. yeast carbon base with $0.01 \%$ ammonium sulfate), conjugated pairs of cells gave rise to asci containing one to four spherical ascospores (Fig. 2), from which single spores were not liberated. The species is homothallic, as conjugation takes place between cells of a single haploid population. Glucose, sucrose and maltose are fermented weakly. D-Glucose, Dgalactose (slow), sucrose, maltose (slow), trehalose (slow), raffinose (slow), inulin (slow), glycerol, DL-lactate (slow), D-sorbitol (D-glucitol), D-mannitol, salicin and xylitol (slow) are assimilated. No growth occurs on L-sorbose, cellobiose, lactose, melibiose, melezitose, soluble starch, Dxylose, L-arabinose, D-arabinose, D-ribose, L-rhamnose, ethanol, erythritol, ribitol, galactitol, succinate, citrate, myo-inositol, methanol, hexadecane, acetone, ethyl acetate, 2-propanol or gluconate. Positive for assimilation of the nitrogen compounds $\mathrm{N}$-acetylglucosamine, ethylamine. $\mathrm{HCl}$ and cadaverine. Unable to assimilate lysine, like L. cidri (Yarrow, 1998) and L. nothofagi (Mestre et al., 2010). Like L. nothofagi, it cannot assimilate nitrate (Mestre et al., 2010). Growth in amino acid-free medium is positive. Grows at $30{ }^{\circ} \mathrm{C}$, but not at $37{ }^{\circ} \mathrm{C}$. Does not grow on YM agar with $10 \%$ sodium chloride or on $50 \%$ glucose (50\%)-yeast extract $(0.5 \%)$ medium. Starch-like compounds are not produced. Negative for growth in $10 \mathrm{mg}$ cycloheximide $\mathrm{ml}^{-1}$, urease activity and the diazonium Blue $\mathrm{B}$ reaction.

The type strain is URM $5925^{\mathrm{T}}\left(=\mathrm{CLIB} 1160^{\mathrm{T}}=\mathrm{CBS}\right.$ $\left.11717^{\mathrm{T}}\right)$, isolated from the cachaça fermentation process.

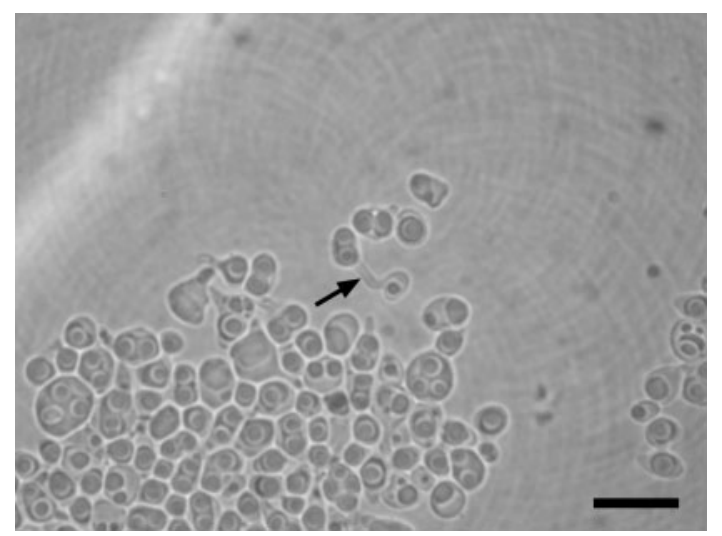

Fig. 2. Vegetative cells and asci containing one to four spherical ascospores of Lachancea mirantina URM $5925^{\top}$ after 3 days of incubation on yeast carbon base medium supplemented with $100 \mathrm{mg}$ ammonium sulfate $\mathrm{I}^{-1}$ at $28^{\circ} \mathrm{C}\left( \pm 2{ }^{\circ} \mathrm{C}\right)$. Arrow indicates the halter structure typical of members of the Zygosaccharomyces/ Lachancea clade. Bar, $10 \mu \mathrm{m}$. 


\section{Acknowledgements}

The authors thank Professor Carlos Augusto Rosa (Department of Microbiology, Federal University of Minas Gerais, Brazil) for his kindly help in this work and the distillery Mirante da Cachaça for their help in the study of yeast population in its process. This work was supported by grants from the funding program PROMATAFACEPE of Pernambuco State and by grants from the Brazilian agency Conselho Nacional de Desenvolvimento Cientifico e Tecnologico (CNPq).

\section{References}

Basilio, A. C. M., de Araújo, P. R. L., de Morais, J. O. F., da Silva Filho, E. A., de Morais, M. A., Jr \& Simões, D. A. (2008). Detection and identification of wild yeast contaminants of the industrial fuel ethanol fermentation process. Curr Microbiol 56, 322-326.

da Silva-Filho, E. A., Brito dos Santos, S. K., Resende, Ado. M., de Morais, J. O., de Morais, M. A., Jr \& Ardaillon Simões, D. (2005). Yeast population dynamics of industrial fuel-ethanol fermentation process assessed by PCR-fingerprinting. Antonie van Leeuwenhoek 88, 13-23.

de Souza Liberal, A. T., Basílio, A. C. M., do Monte Resende, A., Brasileiro, B. T., da Silva-Filho, E. A., de Morais, J. O., Jr, Simões, D. A. \& de Morais, M. A., Jr (2007). Identification of Dekkera bruxellensis as a major contaminant yeast in continuous fuel ethanol fermentation. J Appl Microbiol 102, 538-547.

Fell, J. W., Statzell-Tallman, A. \& Kurtzman, C. P. (2004). Lachancea meyersii sp. nov., an ascosporogenous yeast from mangrove regions in the Bahama Islands. Stud Mycol 50, 359-363.

Felsenstein, J. (1985). Confidence limits on phylogenies: an approach using the bootstrap. Evolution 39, 783-791.

Gomes, F. C. O., Silva, C. L. C., Marini, M. M., Oliveira, E. S. \& Rosa, C. A. (2007). Use of selected indigenous Saccharomyces cerevisiae strains for the production of the traditional cachaça in Brazil. J Appl Microbiol 103, 2438-2447.

Hall, T. A. (1999). BioEdit: a user-friendly biological sequence alignment editor and analysis program for Windows 95/98/NT. Nucleic Acids Symp Ser 41, 95-98.

Kimura, M. (1980). A simple method for estimating evolutionary rates of base substitutions through comparative studies of nucleotide sequences. J Mol Evol 16, 111-120.

Kurtzman, C. P. (2003). Phylogenetic circumscription of Saccharomyces, Kluyveromyces and other members of the Saccharomycetaceae, and the proposal of the new genera Lachancea, Nakaseomyces,
Naumovia, Vanderwatozyma and Zygotorulaspora. FEM Yeast Res 4, 233-245.

Kurtzman, C. P. \& Robnett, C. J. (1998). Identification and phylogeny of ascomycetous yeasts from analysis of nuclear large subunit (26S) ribosomal DNA partial sequences. Antonie van Leeuwenhoek 73, 331371.

Kurtzman, C. P. \& Robnett, C. J. (2003). Phylogenetic relationships among yeasts of the 'Saccharomyces complex' determined from multigene sequence analyses. FEM Yeast Res 3, 417-432.

Lachance, M. A., Daniel, H. M., Meyer, W., Prasad, G. S., Gautam, S. P. \& Boundy-Mills, K. (2003). The D1/D2 domain of the large-subunit rDNA of the yeast species Clavispora lusitaniae is unusually polymorphic. FEM Yeast Res 4, 253-258.

Lee, C. F., Yao, C. H., Liu, Y. R., Hsieh, C. W. \& Young, S. S. (2009). Lachancea dasiensis sp. nov., an ascosporogenous yeast isolated from soil and leaves in Taiwan. Int J Syst Evol Microbiol 59, 1818-1822.

Mestre, M. C., Ulloa, J. R., Rosa, C. A., Lachance, M. A. \& Fontenla, S. (2010). Lachancea nothofagi sp. nov., a yeast associated with Nothofagus species in Patagonia, Argentina. Int J Syst Evol Microbiol 60, 2247-2250.

Oliveira, E. S., Cardello, H. M. A. B., Jeronimo, E. M., Souza, E. L. R. \& Serra, G. E. (2005). The influence of different yeasts on the fermentation, composition and sensory quality of cachaça. World J Microbiol Biotechnol 21, 707-715.

Pataro, C., Guerra, J. B., Petrillo-Peixoto, M. L., Mendonça-Hagler, L. C., Linardi, V. R. \& Rosa, C. A. (2000). Yeast communities and genetic polymorphism of Saccharomyces cerevisiae strains associated with artisanal fermentation in Brazil. J Appl Microbiol 89, 24-31.

Posada, D. \& Crandall, K. A. (1998). MODELTEST: testing the model of DNA substitution. Bioinformatics 14, 817-818.

Saitou, N. \& Nei, M. (1987). The neighbor-joining method: a new method for reconstructing phylogenetic trees. Mol Biol Evol 4, 406425.

Swofford, D. L. (2002). PAUP ${ }^{\star} 4.0 \mathrm{~b} 8$ : Phylogenetic analysis using parsimony (and other methods), version 4. Sunderland, MA: Sinauer Associates.

Vila Nova, M. X., Schuler, A. R., Brasileiro, B. T. \& Morais, M. A., Jr (2009). Yeast species involved in artisanal cachaça fermentation in three stills with different technological levels in Pernambuco, Brazil. Food Microbiol 26, 460-466.

Yarrow, D. (1998). Methods for the isolation and identification of yeasts. In The Yeasts, a Taxonomic Study, 4th edn, pp. 77-100. Edited by C. P. Kurtzman \& J. W. Fell. Amsterdam: Elsevier. 